\title{
PRODUÇÃO DE BIOMASSA E CRESCIMENTO DE ÁRVORES DE Schizolobium amazonicum (Huber) Ducke SOB DIFERENTES ESPAÇAMENTOS NA REGIÃO DE MATA ${ }^{1}$
}

\author{
Eliazel Vieira Rondon ${ }^{2}$
}

\begin{abstract}
RESUMO - O ensaio foi conduzido no município de Sinop, Estado de Mato Grosso. Aos 60 meses de idade foram avaliados a altura total, o diâmetro à altura do peito (DAP), o número de plantas danificadas pelo vento e a produção de biomassa da parte aérea de Schizolobium amazonicum, em diferentes densidades populacionais e espaçamentos. Os resultados demonstram que o crescimento em altura e DAP foram influenciados nos diferentes espaçamentos estudados. Quarenta e sete plantas úteis foram danificadas pelo vento, e quanto à biomassa o espaçamento 4x4 m resultou em produção de biomassa superior à dos demais espaçamentos.
\end{abstract}

Palavras-chave: Schizolobium amazonicum, densidade populacional, espaçamento e produção de biomassa.

\section{BIOMASS YIELD AND GROWTH OF Schizolobium amazonicum (Huber) Ducke UNDER DIFFERENT SPACING CONDITIONS IN THE WOOD REGION}

\begin{abstract}
An assay was carried out at Sinop, Mato Grosso. Total height, number of wind-damaged plants and biomass yield of Schizolobium amazonicum were evaluated in different populational densities and spacings, at sixty months of age. The results show that height and DBH developments were influenced in the different spacings studied. Forty seven plants were wind-damaged and the $4 \times 4 \mathrm{~m}$ spacing yielded more biomass than the other spacings.
\end{abstract}

Key words: $\quad$ Schizolobium amazonicum, population density, spacing and biomass yield.

\section{INTRODUÇÃO}

O Schizolobium amazonicum (Huber) Ducke. é uma espécie florestal conhecida vulgarmente como pinhocuiabano ou paricá. No Estado de Mato Grosso o plantio com essa espécie teve seu incremento na década de 90 e concentrou-se na região norte, sendo sua madeira utilizada pelas indústrias de compensados.

O paricá é uma árvore grande que ocorre em mata primária e secundária de terra-firme e várzea alta, apresentando rápido crescimento (Ducke, 1949). Os trabalhos relacionados com a silvicultura dessa espécie ainda são poucos (Marques, 1990).
Randon (2000), avaliando 30 espécies florestais com 54 meses de idade, constatou que o paricá está se destacando em crescimento e forma de plantio.

O espaçamento utilizado atualmente pelas principais empresas reflorestadoras do Brasil tem sido escolhido para possibilitar a mecanização das atividades de implantação, manutenção e exploração dos maciços florestais, motivo pelo qual tem sido dada preferência aos espaçamentos com aproximadamente $3 \mathrm{~m}$ entre as linhas (Bernardo, 1995). O espaçamento pode afetar o desenvolvimento e a produtividade das florestas plantadas, principalmente para as espécies de rápido crescimento; o espaçamento inadequado pode acentuar os efeitos da

1 Recebido para publicação em 15.2.2001.

Aceito para publicação em 6.11.2002.

2 Eng. Florestal, Pesquisador da EMPAER-MT, Rua das Pitangueiras, 84, 78.550-000 Sinop-MT, Fone: (66) 531-1215, Fax: (66) 531-1611. 
deficiência hídrica sobre as plantas, diminuindo a produtividade da floresta, em razão da intensa competição intra-específica por água, nutrientes, luz e espaço (Leles et al., 1998).

Vale et al. (1982) e Leite et al. (1997) observaram que a adoção de espaçamentos muito reduzidos acarretam a produção de toras de pequeno diâmetro e muitas árvores dominadas, o que compromete o volume final produzido. É de primordial importância a definição de espaçamentos adequados para as diversas espécies nativas com potenciais para reflorestamento.

O presente trabalho teve por objetivo avaliar o crescimento e a produção de biomassa da parte aérea de Schizolobium amazonicum (paricá), assim como o efeito do vento aos 60 meses de idade, de modo a obter subsídios para definir um espaçamento mais apropriado à região de mata.

\section{MATERIAL E MÉTODOS}

O experimento foi conduzido na área da Empresa Mato-Grossense de Pesquisa Assistência e Extensão Rural S.A. - EMPAER-MT, situada no município de Sinop, no norte do Estado, com latitude de $11^{\circ} 50^{\prime} \mathrm{S}$, longitude $55^{\circ} 38^{\prime} \mathrm{W}$ e altitude de $384 \mathrm{~m}$. As médias da temperatura máxima e mínima mensais são 34 e $24^{\circ} \mathrm{C}$, respectivamente, e a precipitação média anual de $2.090 \mathrm{~mm}$. Essa região é caracterizada como zona de transição edafoclimática entre cerrado e floresta amazônica, sua vegetação é classificada como floresta semidecidual submontana dossel emergente e seu clima, segundo Köppen, é do tipo Aw (Brasil, 1980). O solo apresenta baixa fertilidade, sendo classificado como Latossolo Vermelho-Amarelo distrófico, textura argila arenosa, com $\mathrm{pH}$ em água 4,5, baixo teores de $\mathrm{K}$ e $\mathrm{P}, 2,0 \%$ de $\mathrm{V}$ e $2,4 \%$ de matéria orgânica, $54 \%$ de areia, $6 \%$ de silte e $40 \%$ de argila.

A área foi aberta com trator de esteira e queimada na leira. Depois de marcadas as parcelas, realizou-se o coveamento. Os tratos culturais e a adubação obedeceram à mesma recomendação preconizada no documento Técnicas para o Cultivo de Seringueiras no Estado de Mato Grosso (Santos et al., 1994). A adubação de plantio constou de $50 \mathrm{~g}$ de sulfato de amônia, $100 \mathrm{~g}$ de superfosfato simples, $50 \mathrm{~g}$ de cloreto de potássio, adicionandose também 21 de cinza, 21 de esterco de gado curtido, 11 de esterco de galinha, 31 de vinhoto e $100 \mathrm{~g}$ de calcário. Procedeu-se a duas adubações químicas anuais em cobertura (início e fim do período chuvoso) a dois terços da projeção da copa em sulco, no sistema de meialua, na mesma proporção que a da adubação da cova. A semente é originada de matrizes do município de Juara. Realizou-se a quebra da dormência com água quente, até atingir temperatura ambiente, semeando-se em sacos plásticos com dimensões de $18 \mathrm{~cm}$ de largura por $25 \mathrm{~cm}$ de comprimento e $0,002 \mathrm{~cm}$ de espessura, preenchida com substratos (três partes de terra de subsolo e uma parte de esterco de galinha). Quando a muda atingiu $20 \mathrm{~cm}$ de altura iniciou-se o plantio, no dia 4 de dezembro de 1995. Foram avaliados os seguintes espaçamentos: 1,5x1,5 m, $2 \times 2 \mathrm{~m}, 3 \times 2 \mathrm{~m}, 3 \times 3 \mathrm{~m}, 4 \times 2 \mathrm{~m}, 4 \times 3 \mathrm{~m}, 4 \times 4 \mathrm{~m}$. O delineamento utilizado foi o bloco ao acaso, com sete tratamentos (espaçamentos) e três repetições. Foram plantadas 525 plantas no total, tendo sido avaliadas 27 árvores centrais por tratamento.

As avaliações relativas à altura das plantas, ao diâmetro à altura do peito (DAP) e ao número de plantas danificadas pelo vento foram realizadas anualmente. Para avaliação da biomassa vegetal da parte aérea, em cada espaçamento, foi abatida uma árvore com DAP médio, tendo sido separados e pesados os seus componentes, isto é, folhas, galhos e tronco. A amostragem do tronco foi feita ao retirar três discos (base, meio e topo) de $5 \mathrm{~cm}$ de espessura. As amostras foram levadas ao laboratório e secas em estufa de ventilação forçada a $70^{\circ} \mathrm{C}$, até o peso constante, e pesadas novamente para obter o peso da matéria seca. A partir da relação entre o peso de matéria seca e matéria fresca, determinou-se o seu teor de umidade e, finalmente, calculou-se a biomassa de cada componente. $\mathrm{O}$ peso de matéria seca da parte aérea, em toneladas por hectare, para os diferentes componentes da planta, foi calculado ao considerar a densidade populacional de cada espaçamento, admitindo-se uma sobrevivência igual a $100 \%$.

\section{RESULTADOS E DISCUSSÃO}

No Quadro 1 estão apresentados os resultados das análise de variâncias para altura, diâmetro à altura do peito (DAP) e produção de biomassa total da parte aérea das plantas, bem como seus componentes folhas, galhos e tronco.

Nota-se que nos espaçamentos mais amplos, destacando-se 4x3 m (833 plantas/ha) e 4x4 m (625 plantas/ha), as plantas apresentaram alturas e diâmetros médios superiores, ocorrendo o inverso com os espaçamentos 
Q uadro 1 - Comparação das médias para altura diâmetro à altura do peito (DAP) e matéria seca das folhas, dos galhos, do tronco e total deSchizolobium amazonicum em diferentes espaçamentos, aos 60 meses de idade

Table 1 - Average comparisons for height, diameter at breast height (DBH), and dry matter of leaf branches, stem and total of Schizolobium amazonicum at different spacings at 60 months of age

\begin{tabular}{|c|c|c|c|c|c|c|}
\hline \multirow{2}{*}{$\begin{array}{c}\text { Espaçamento } \\
\text { (m) }\end{array}$} & \multirow{2}{*}{$\begin{array}{l}\text { Altura } \\
(\mathrm{m})\end{array}$} & \multirow{2}{*}{$\begin{array}{l}\text { DAP } \\
(\mathrm{cm})\end{array}$} & Folhas & Galhos & Tronco & Total \\
\hline & & & \multicolumn{4}{|c|}{ (t/ha) } \\
\hline $1,5 \times 1,5$ & $11,5 \mathrm{BCD} *$ & $11,3 \mathrm{BCD}$ & $12,80 \mathrm{~B}$ & $5,30 \mathrm{~B}$ & $56,30 \mathrm{~B}$ & $74,40 \mathrm{BC}$ \\
\hline $2 \times 2$ & $14,0 \mathrm{BC}$ & $13,4 \mathrm{BCD}$ & $9,20 \mathrm{~B}$ & $3,00 \mathrm{~B}$ & $46,80 \mathrm{BC}$ & $59,00 \mathrm{C}$ \\
\hline $3 \times 2$ & $18,0 \mathrm{~B}$ & $15,6 \mathrm{BC}$ & $19,90 \mathrm{~A}$ & $3,30 \mathrm{~B}$ & $59,20 \mathrm{~B}$ & $82,40 \mathrm{~B}$ \\
\hline $3 \times 3$ & $19,0 \mathrm{BC}$ & $16,6 \mathrm{AB}$ & $11,20 \mathrm{~B}$ & $5,50 \mathrm{~B}$ & $63,10 \mathrm{~B}$ & $79,80 \mathrm{BC}$ \\
\hline $4 \times 2$ & $16,0 \mathrm{BCD}$ & $15,1 \mathrm{BC}$ & $8,20 \mathrm{~B}$ & $5,80 \mathrm{~A}$ & $71,40 \mathrm{~A}$ & $85,40 \mathrm{AB}$ \\
\hline $4 \times 3$ & $21,5 \mathrm{~A}$ & $17,4 \mathrm{~A}$ & $14,10 \mathrm{~A}$ & $6,10 \mathrm{~A}$ & $49,90 \mathrm{BC}$ & $70,10 \mathrm{BC}$ \\
\hline $4 \times 4$ & $20,0 \mathrm{AB}$ & $19,5 \mathrm{~A}$ & $11,80 \mathrm{~B}$ & $6,00 \mathrm{~A}$ & $74,80 \mathrm{~A}$ & $92,60 \mathrm{~A}$ \\
\hline
\end{tabular}

* Médias seguidas pela mesma letra nas colunas não diferem estaticamente pelo teste Tukey, a 5\%.

menores. Estes resultados estão de acordo com os trabalhos de Bernardo (1995) e Assis et al. (1999). Porém, é importante que sejam obtidos dados mais próximos à idade de rotação, para que se tenha melhor definição do espaçamento adequado.

A definição do espaçamento para plantio florestal é de grande importância, considerando a sua influência na taxa de crescimento, no valor e na qualidade da matériaprima, no manejo, na exploração florestal, nos custos de produção (Balloni \& Simões, 1980; Simões et al., 1981; Balloni, 1983).

Conforme Patiño - Valera (1986), o espaçamento ótimo é aquele capaz de produzir o maior volume de produto em tamanho, forma e qualidade desejáveis, sendo função da espécie do sítio e do potencial genético do material reprodutivo que for utilizado.

Foram 47 plantas danificadas pelo vento, correspondendo a $24,8 \%$ das plantas úteis. Os espaçamentos $4 \times 2 \mathrm{~m}$ e 2x2 m apresentaram, respectivamente, 8,9 e 6,3\%. Até o terceiro ano essa espécie florestal (paricá) é altamente vulnerável ao vento, portanto medida preventiva deve ser adotada no início da implantação do reflorestamento, deixando uma faixa de mata nativa e evitando o plantio homogêneo.

Quanto à produção de biomassa total da parte aérea das plantas, bem como aos seus componentes folhas, galhos e tronco, percebe-se inicialmente que o espaçamento testado conduziu a diferentes produções de biomassa total. Verifica-se que a maior contribuição foi do tronco, com 77\%. Dados semelhantes foram também observados com Eucalyptus spp. por Pereira (1990), Bernardo (1995) e Leles (1995). As folhas tiveram $16 \%$ e os galhos $7 \%$ da produção de biomassa total. As menores produções estão relacionadas aos espaçamentos $2 \times 2 \mathrm{~m}, 4 \times 3 \mathrm{~m}$ e 1,5x1,5 m e as maiores, aos espaçamentos $4 \times 4 \mathrm{~m} \mathrm{e} \mathrm{4 \times 2} \mathrm{m.}$ A influência de diferentes espaçamentos sobre a produção de biomassa varia com a espécie, a idade das plantas e a qualidade de sítio (Bernardo, 1995). Observou-se em povoamento de $E$. grandis que o tronco representava $33,4 \%$ da biomassa da parte aérea, enquanto folhas e galhos, 64,18\%, devendo-se ressaltar que aos sete anos somente o tronco contribui com $94,8 \%$ de toda a matéria seca (Bellote, 1979).

\section{CONCLUSÕES}

O aumento da densidade populacional promoveu redução da altura e diâmetro das plantas de Schizolobium amazonicum.

Os espaçamentos $4 \times 3 \mathrm{~m}$ e $4 \times 4 \mathrm{~m}$ proporcionaram maiores crescimentos.

O paricá é uma espécie florestal sensível ao vento forte, portanto medidas preventivas devem ser adotadas no início da implantação do reflorestamento.

A produção de biomassa total da parte aérea concentrou-se principalmente no tronco da árvore.

R. Árvore, Viçosa-MG, v.26, n. 5, p.573-576, 2002 


\section{REFERÊNCIAS BIBLIOGRÁFICAS}

ASSIS, R. L. et al. A produção de biomassa de Eucalyptus urophylla $\mathrm{S}$. T. Blake sob diferentes espaçamentos na região de cerrado de Minas Gerais. Revista Árvore, v. 23, n. 2, p. 151-156, 1999.

BALLONI, E. A. Influência do espaçamento de plantio na produtividade florestal. Silvicultura, v. 8, n. 31, p. 558$592,1983$.

BALLONI, E. A.; SIMÕES, J. W. O espaçamento do plantio e suas implicações silviculturais. Piracicaba: IPEF, 1980. 16 p. (Série Técnica, 3).

BELLOTE, A. F. J. Concentração, acúmulo e exportação de nutrientes pelo Eucalyptus grandis em função da idade. Piracicaba: Escola Superior de Agricultura Luiz de Queiroz, 1979. 129 p. Mestrado (Engenharia Florestal) Escola Superior de Agricultura "Luiz de Queiroz”, 1979.

BERNARDO, A. L. Crescimento e Eficiência nutricional de Eucalyptus spp. Sob Diferentes espaçamentos na região de cerrado de Minas Gerais. Viçosa-MG: Universidade Federal de Viçosa, 1995. 102p. Dissertação (Mestrado em ciência Florestal) - Universidade Federal de Viçosa, 1995.

BRASIL. Ministério de Minas de Energia: Departamento Nacional da produção mineral. Projeto RADAM Brasil. Folhas sc. 21. Juremo: Geomorfologia, pedologias, vegetação e uso potencial da terra. Rio de Janeiro: 1980. 460 p. (Levantamento de Recursos Naturais, v. 20).

DUCKE, A. Notas sobre a flora neotrópica II: As leguminosas da Amazônia brasileira. 2.ed. Belém, IAN 1949. 248 p. (IAN Boletim Técnico, 18).

LEITE, F. P. et al. Crescimento de Eucalyptus grandis em diferentes densidades populacionais. Revista árvore, v. 21, n. 3, p. 313-321, 1997.

LELES, P. S. S. Crescimento alocação de biomassa e distribuição de nutrientes e uso de água em $E$. camaldulensis e $\boldsymbol{E}$. pellita sob diferentes espaçamentos. Viçosa: Universidade Federal de Viçosa, 1995. 133 p. Dissertação (Mestrado em Solo e Nutrição de Plantas) Universidade Federal de Viçosa, 1995.
LELES, P. S. S. et al. Relações hídricas e crescimento de árvores de Eucalyptus camaldulensis e Eucalyptus pellita sob diferentes espaçamentos na região de cerrado. Revista Árvore, v. 22, n. 1, p. 41-50, 1998.

MARQUES, C. L. T. Comportamento inicial de paricá, tatajuba e eucalipto, em plantio consorciado com milho e capim-marandu, em Paragominas, PARÁ. Viçosa-MG: Universidade Federal de Viçosa, 1990. 92 p. Dissertação (Mestrado em Ciência Florestal) - Universidade Federal de Viçosa, 1990.

PATIÑO-VALERA, F. Variação genética em progênies de Eucalyptus saligna Smith e sua interação com espaçamento. Piracicaba: Escola Superior de Agricultura "Luiz de Queiroz", 1986. 192 p. Dissertação (Mestrado em Engenharia Florestal) - Escola Superior de Agricultura "Luiz de Queiroz", 1986.

PEREIRA, A. R. Biomassa e ciclagem de nutrientes minerais em povoamentos jovens de Eucalyptus grandis e Eucalyptus urophylla em região de cerrado. Viçosa-MG: Universidade Federal de Viçosa, 1990. 167 p. Tese (Doutorado em Solos e Nutrição de Plantas) - Universidade Federal de Viçosa, 1990..

RONDON, E. V. Comportamento de Essências Florestais Nativas e Exóticas no Norte de Mato Grosso. In; FLOREST 2000 - CONGRESSO E EXPOSIÇÃO INTERNACIONAL SOBRE FLORESTAS, 6., 2000. Porto Seguro, BA. Resumos Técnicos... Porto Seguro: BIOSFERA, 2000. p. 68 .

SANTOS, A. M. et al. Técnicas para o cultivo da seringueira no Estado de Mato Grosso. Cuiabá: EMPAER-MT, 1994. 40 p. (Documento, 8).

SIMÕES, J. W.; BRANDI, T. M.; LEITE, N. B. Formação, manejo e exploração de florestas de rápido crescimento. Brasília: IBDF, 1981. 131 p.

VALE, A. B. et al. Influência do espaçamento e do sítio na produção florestal. Viçosa-MG: SIF, 1982. 20 p. (Boletim Técnico, 4). 